OPEN

SUBJECT AREAS: ECOPHYSIOLOGY

METABOLISM

Received

24 July 2014

Accepted

4 November 2014

Published

20 November 2014

Correspondence and requests for materials should be addressed to M.Y. (yagi-m@ nagasaki-u.ac.jp; yagi@kyudai.jp)

\section{Ontogenetic phase shifts in metabolism in a flounder Paralichthys olivaceus}

\author{
Mitsuharu Yagi' \& Shin Oikawa
}

\author{
${ }^{1}$ Faculty of Fisheries, Nagasaki University, Bunkyo, Nagasaki 852-8521, Japan, ${ }^{2}$ Fishery Research Laboratory, Graduate School of \\ Bioresource and Bioenvironmental Sciences, Kyushu University, Fukuoka 811 1-3304, Japan.
}

Size-scaling metabolism is widely considered to be of significant importance in biology and ecology. Thus, allometric relationships between metabolic rate $\left(\dot{V}_{O 2}\right)$ and body mass $(M), \dot{V}_{O 2}=\mathrm{a}_{\mathrm{i}} M^{\mathrm{b}}$, have long been a topic of interest and speculation. It has been proposed that intraspecifically metabolic rate scales isometrically or near isometrically with body mass during the early life history in fishes, invertebrates, birds and mammals. We developed a new perspective on intraspecific size-scaling metabolism through determination of metabolic rate in the Japanese flounder, Paralichthys olivaceus, during their early life stages spanning approximately four orders of magnitude in body mass. With the increase of body mass, the Japanese flounder had four distinct negative allometric phases in which three stepwise increases in scaling constants $\left(a_{i}, i=1-4\right)$, i.e. ontogenetic phase shifts in metabolism, occurred with growth during its early life stages at around $0.002,0.01$ and $0.2 \mathrm{~g}$, maintaining each scaling exponent constant in each phase $(b=0.831)$. These shifts in metabolism during the early life stages are similar to the tiger puffer, Takifugu rubripes. Our results indicate that ontogenetic phase shifts in metabolism are key to understanding intraspecific size-scaling metabolism in fishes.

M etabolic rate of living things is related to many biological traits such as body size, growth, phylogeny of species, rates of reproduction and genome evolution ${ }^{1-7}$. Body size of animals primarily constrains the metabolic rate through the size-scaling effect ${ }^{8-14}$ and these two traits have co-evolved ${ }^{15}$. It has been established that the relationship between metabolic rate $\left(\dot{V}_{O 2}\right)$ and body mass $(M)$ in animals is expressed by the allometric formula,

$$
\dot{V}_{O 2}=\mathrm{a} M^{\mathrm{b}},
$$

where "a" is a scaling constant and "b" is the scaling exponent. However there are many cases where a simple allometric equation can not explain non-linear or curvilinear log-log metabolic scaling relationships ${ }^{16-19}$. Furthermore intraspecific size-scaling metabolism of animals may be a complex process in which several phases can be distinguished ${ }^{16,20-22}$.

Fishes are good candidates for intraspecific studies because, unlike other vertebrates such as mammals, birds or reptiles, most fishes develop from a small body size (mg level or less) $)^{23,24}$ and attain a mass range approximately comparable to that between a mouse and an elephan ${ }^{25}$. In addition, it is not necessary to consider the phylogeny of species ${ }^{26-28}$. Although reported scaling exponents in various species of fish are quite variable (approximately 0.4 to 1.3$)^{26,29}$, a scaling exponent has often been suggested as close to unity in the early stages of development of marine fish larvae ${ }^{30}$. On the other hand, in juveniles and adults, the relationship between metabolic rate and body mass is negatively allometric, and the mass exponents for simple regression of metabolic rate on body mass are usually less than 1 . Consequently, a biphasic relationship where the scaling exponent changes from isometry or near isometry during the larval phase to negative allometry during the juvenile phase has been proposed in many fish species ${ }^{25,31-34}$. Although these studies concluded that both the metabolic scaling exponent and scaling constant varies during ontogeny, the generality of the isometric scaling remains an open question requiring additional empirical evidence.

Recently we have demonstrated that in the larval and juvenile tiger puffer, Takifugu rubripes, oxygen consumption $\left(\dot{V}_{\mathrm{O} 2}\right)$, as a proxy for metabolism, scales with $M$ as $\dot{V}_{O 2}=\mathrm{a}_{\mathrm{i}} M^{0.795}$, and that three stepwise increases in scaling constants $\mathrm{a}_{\mathrm{i}}(\mathrm{i}=1-4)$, i.e. ontogenetic phase shifts in metabolism, occur, maintaining each scaling exponent constant in each phase ${ }^{22}$. The overall scaling exponent $(0.948 \pm 0.002)$ (estimate \pm s.e.m.) was steeper than the scaling exponents for each developmental stage $(0.795 \pm 0.019)^{22}$. This result suggests that isometric or nearisometric metabolic scaling during early life stages may be produced by a combined effect of ontogenetic phase 
shifts in metabolism. Thus, ontogenetic shifts in metabolism are likely to occur in other teleost fish species. In the present paper, we examine if the ontogenetic phase shifts in metabolism occur with growth in the Japanese flounder Paralichthys olivaceus (Temminck \& Schlegel, 1846).

\section{Results}

Rates of oxygen consumption $\left(\dot{V}_{\mathrm{O} 2}\right.$ in $\mu \mathrm{O}_{2}$ fish $\left.^{-1} \mathrm{~min}^{-1}\right)$ in relation to body mass ( $M$ in $\mathrm{g}$ ) are plotted in Figure 1. Mass-specific rates of oxygen consumption $\left(\dot{V}_{\mathrm{O} 2} / \mathrm{M}\right.$ in $\mu \mathrm{O}_{2} \mathrm{~g}^{-1} \mathrm{~min}^{-1}$ ) are also presented. $\dot{V}_{O 2}$ increased daily from just after hatching to 7 days after hatching (DAH), with virtually no increase of body mass. After $7 \mathrm{DAH}$, body mass increased. There was no substantial difference between the results of the two different methods of respirometry (Figure 1). Therefore, the values obtained were used without any distinction for the relationship between oxygen consumption and body mass.

Two models were applied to compare the four negative allometric relationships:

$$
\dot{V}_{\mathrm{O} 2}=\mathrm{a}_{\mathrm{i}} M^{\hat{\mathrm{b}}},
$$

for each incidence of negative allometry, and

$$
\dot{V}_{\mathrm{O} 2}=\alpha M^{\overline{\mathrm{b}}}
$$

for the overall line constituting these allometries ${ }^{35,36}$. ' $a_{i}$ ' represents an intragroup scaling constant of the $i$ 'th group, and ' $\alpha$ ' the intergroup one of the groups. Equations (2) and (3) were rewritten as

$$
y_{i j}=\log _{10} a_{i}+\hat{b} x_{i j}+\varepsilon_{i j},
$$

and

$$
y_{i j}=\log _{10} \alpha+\overline{\mathrm{b}} x_{i j}+E_{i j},
$$

where $y_{i j}$ is $\log _{10} \dot{V}_{O 2}, x_{i j}$ is $\log _{10} M$ and $\varepsilon_{i j}$ and $E_{i j}$ represent the random intra- and intergroup variation in metabolism. To estimate $\bar{b}$ and $\log _{10} \alpha$, we used the ordinary least-squares regression to minimise the sum of squares of $\mu_{i}$, which is the vertical distance of the group mean $\left(\bar{x}_{i}, \bar{y}_{i}\right)$ from the overall line (intergroup line) ${ }^{35}$. Because $\log _{10} a_{i}$ is equal to $\left(\log _{10} \alpha+\mu_{i}+(\bar{b}-\hat{b}) \bar{x}_{i}\right)$, Equation (4) was rewritten as follows ${ }^{22,36}$ :

$$
y_{i j}=\log _{10} \alpha+\mu_{i}+(\overline{\mathrm{b}}-\hat{\mathrm{b}}) \bar{x}_{i}+\hat{\mathrm{b}} x_{i j}+\varepsilon_{i j} .
$$

The scaling exponents of individual lines were significantly smaller than unity for all regression lines $(P<0.05$; two tailed t-test). Regression analysis of each group, except the transitional phases is given in rows 1 to 4 of Table 1 . The slopes of the individual lines in each of the four groups were not significantly different $\left(F_{3,94}=1.95\right.$, $P=0.127$; one-way ANCOVA). The intragroup scaling exponent $\hat{b}$ was estimated to be $0.831 \pm 0.0026$ (estimate \pm S.E.M.), and logarithm of the scaling constants in each group at $\hat{b}=0.831$ was estimated as follows: $\log _{10} \mathrm{a}_{1}=0.373 \pm 0.083, \log _{10} \mathrm{a}_{2}=0.425 \pm 0.062$, $\log _{10} \mathrm{a}_{3}=0.539 \pm 0.034$, and $\log _{10} \mathrm{a}_{4}=0.584 \pm 0.018$. The scaling constants were calculated as follows: $\mathrm{a}_{1}=2.36, \mathrm{a}_{2}=2.66, \mathrm{a}_{3}=3.46$, and $\mathrm{a}_{4}=3.84$. Regression analysis of the intergroup is given in rows $5-7$ of Table 1 . The intergroup scaling exponents $\bar{b}$ was estimated to be $0.915 \pm 0.0011$.

A one-way ANCOVA was carried out to clarify the validity of Equation (6), and the results are provided in Table 2. The $\mu_{i}$ 's were not different from zero $\left(F_{2,97}=1.71, P=0.186\right.$; one-way ANCOVA), meaning that the intragroup means might lie on the intergroup

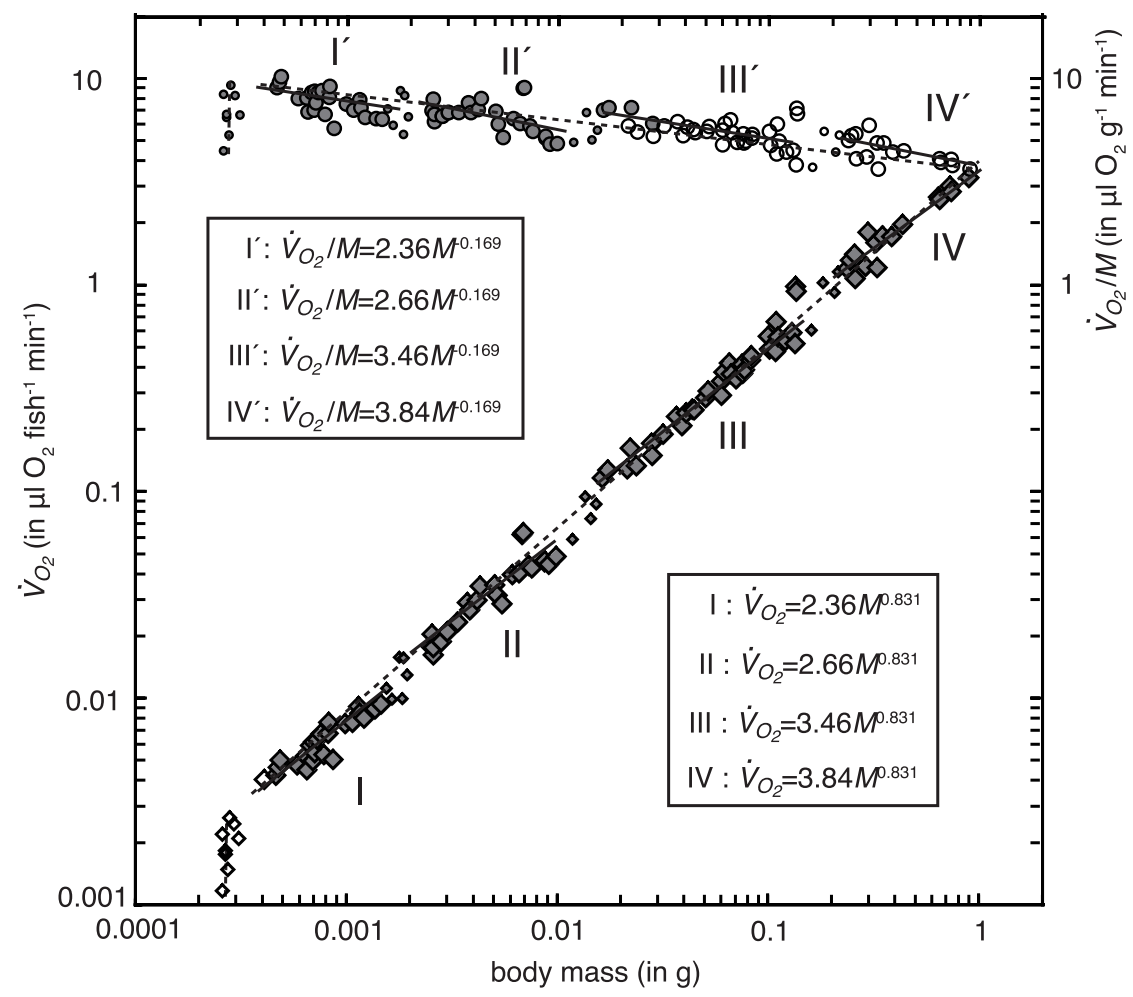

Figure $1 \mid$ Ontogenetic changes in the rate of respiration $\left(\dot{V}_{\mathrm{O} 2}\right.$, diamonds) and the mass-specific rate of respiration $\left(\dot{V}_{\mathrm{O}_{2}} / \mathrm{M}\right.$, circles) with increase of body mass $(M)$ in Japanese flounder. Symbols for $\dot{V}_{O 2}$ indicate the two methods of respirometry (open: closed method and solid: semi-closed method). Symbols for $\dot{V}_{\mathrm{O} 2} / \mathrm{M}$ signify the year in which data were collected (open: 2005 and solid: 2006). The vertical broken lines at around $0.0003 \mathrm{~g}$ represent $\dot{V}_{\mathrm{O} 2}$ and $\dot{V}_{\mathrm{O} 2} / M$ which increased daily from just after hatching to 7 days after hatching, with virtually no increase in body mass. Ranges covered by the four solid lines each for $\dot{V}_{\mathrm{O} 2}$ and $\dot{V}_{\mathrm{O} 2} / \mathrm{M}$ indicate intragroup phases of negative allometry. The broken lines both on $\dot{V}_{\mathrm{O} 2}$ and $\dot{V}_{\mathrm{O} 2} / M$ represent the intergroup lines. Small symbols represent values during the transitional phases. Regression analysis of each line for $\dot{V}_{O 2}$ is presented in Table 1 , and ANCOVA in Table 2. 
Table $1 \mid$ Intragroup (rows 1 to 4), intergroup (rows 5 to 7) regression analysis of the relationship between $\log _{10} \dot{V}_{O 2}\left(\dot{V}_{O 2}\right.$ : oxygen consumption in $\mu \mathrm{O}_{2}$ fish $^{-1} \mathrm{~min}^{-1}$ ) and $\log _{10} M$ (M: body mass in $\mathrm{g}$ ) in the Japanese flounder

\begin{tabular}{|c|c|c|c|c|c|c|}
\hline Group & $N$ & $\frac{\text { Range of body mass }}{\text { (g) }}$ & $\begin{array}{l}\text { Scaling } \\
\text { constant }\end{array}$ & $\begin{array}{l}\text { Scaling exponent } \\
\text { (Mean } \pm \text { S.E.M.) }\end{array}$ & $P$ & $R^{2}$ \\
\hline $1 *$ & 24 & $0.00041-0.0015$ & 0.80 & $0.680 \pm 0.065$ & $6.26 \times 10^{-5}$ & 0.832 \\
\hline $3 *$ & 36 & $0.016-0.14$ & 3.92 & $0.875 \pm 0.035$ & $1.12 \times 10^{-3}$ & 0.948 \\
\hline $4^{*}$ & 16 & $0.24-0.90$ & 3.67 & $0.782 \pm 0.066$ & $5.04 \times 10^{-3}$ & 0.910 \\
\hline $1-4^{+}$ & 102 & $0.00041-0.90$ & $\alpha=4.28$ & $\bar{b}=0.915 \pm 0.0011$ & $6.58 \times 10^{-91}$ & 0.9999 \\
\hline
\end{tabular}

*Parameters were estimated to minimise the sum of squares of $\varepsilon$ in each group; ${ }^{\dagger}$ parameters were estimated to minimise the sum of squares of $\mu_{i j}{ }^{5}$ parameters were estimated to minimise the sum of squares of $E_{i}$ "including the transitional phases. $N$ is the number of determinations; $P$ is the difference of scaling exponent from unity, examined using Students $t$-test, two tailed; $R^{2}$ is squared correlation coefficient between $\log _{10} \dot{V}_{O 2}$ and $\log _{10} M$.

(overall) line. The intragroup scaling exponent $\hat{b}=0.831$ was significantly different from the intergroup exponent $\bar{b}=0.915\left(F_{1,97}=9.67\right.$, $P=0.00246$; one-way ANCOVA). This implies that the intragroup scaling constant $\mathrm{a}_{\mathrm{i}}$ increased significantly from $\mathrm{a}_{1}=2.36$ to $\mathrm{a}_{4}=3.84$ with increase in body mass (Figure 1). Thus, the metabolic rate is expressed by $\dot{V}_{\mathrm{O} 2}=\mathrm{a}_{\mathrm{i}} M^{0.831}$, in which $\mathrm{a}_{\mathrm{i}}$ increased three times during the transitional phases.

\section{Discussion}

The size-scaling metabolism for the Japanese flounder during its early life stages (that is, spanning approximately four orders of magnitude in body mass) showed ontogenetic phase shifts, because the scaling constant $a_{i}$ increased three times in the course of development, maintaining each scaling exponent constant in each phase $(\hat{b}=0.831)$ (Figure 1$)$. These shifts in metabolic scaling are consistent with the findings of Yagi et al. ${ }^{22}$, who reported that a puffer fish had four distinct phases in which three stepwise increases in scaling constants, i.e. ontogenetic phase shifts in metabolism, occur with growth during its early life stages, maintaining each scaling exponent constant in each phase $(\hat{b}=0.795)$. However, when comparing the scaling constants for the Japanese flounder to the tiger puffer ones, the range for the Japanese flounder (2.36 to 3.84) was narrower than what was observed in the previous study ${ }^{22}$ for the tiger puffer $(2.75$ to 7.25). This difference in the scaling constants between two species could be attributable to differences in the developmental trajectory. The Japanese flounder larvae initially resemble typical fish swimming in a vertical attitude as well as the tiger puffer. At $\sim 0.01 \mathrm{~g}$, they change their mode of life to swim in a horizontal attitude after metamorphosis, becoming bottom-dwelling fish. Juvenile and later stage Japanese flounder showed almost no activity in respirometers, lying on their floor. Therefore, measures of resting routine metabolic rate closely approximate resting metabolic rate after metamorphosis. The tiger puffer juveniles move to estuary and neighbouring mudflats at $\sim 0.1 \mathrm{~g}$, and grow there for a while in Hakata Bay and Ariake Sound,
$\operatorname{Japan}^{22}$. After that, they show active benthic swimming to migrate to the East China Sea and the Yellow Sea. Although further research is required, our results suggest that differing patterns of development and activity status during ontogeny can cause variation in metabolic scaling between species.

Previously, the intraspecific metabolic rate of larval and juvenile fishes was thought to scale isometrically $(b=1.0)$ or near isometrically to body mass $s^{30,32,33,37-40}$. Isometric or near isometric scaling during early life stages have also been reported in invertebrates, birds and mammals (reviewed in Glazier ${ }^{16}$ ). These reports are not surprising, because isometric or near isometric scaling of metabolic rate may be made by the increases of $a_{i}$ during ontogeny. For example, when the scaling exponent was estimated from $0.00026 \mathrm{~g}(0 \mathrm{DAH})$ to $0.0055 \mathrm{~g}$ (30 DAH), it would be 1 ( $P=0.052$; two tailed t-test) for the Japanese flounder. This suggests that the ontogenetic phase shifts in metabolism during early life stages may not be specific only to the Japanese flounder and the tiger puffer. In fact, further analyses demonstrate that similar sequential shifts in scaling coefficient (a) over development have been observed in the tobacco hornworm ${ }^{41}$. However, Blossman-Myer \& Burggren ${ }^{42}$ have found a different pattern to that found in our study: an overall scaling exponent of 0.82 versus isometric scaling within development stages (instars) of the silkworm. Although a segmented regression was applied in the present study, other functions may be more biologically relevant (e.g. techniques that allow gradual, rather than an abrupt change in the scaling exponent). In any case, we speculate that such hidden ontogenetic phase shifts in metabolism may play a key role in the linear intraspecific size-scaling metabolism that has been observed in animals.

Fishes develop from larvae, whose morphological features are appreciably different from adults, to juveniles which have adult-like features ${ }^{43}$. Previously, the developmental stages during early life for fishes have been distinguished by morphological features, such as yolk-sac, and pre-flexion, flexion and post-flexion larvae ${ }^{44}$. In this study, the ontogenetic phase shifts in metabolism at $\sim 0.002, \sim 0.01$

\begin{tabular}{|c|c|c|c|c|c|}
\hline Term & Sum of squares & $\begin{array}{l}\text { Degrees of } \\
\text { freedom }\end{array}$ & Mean square & $\begin{array}{c}\text { Mean-square } \\
\text { ratio }\end{array}$ & $P$ \\
\hline $\begin{array}{l}\log \alpha \\
\mu_{i} \\
(\bar{b}-\hat{b}) \bar{x}_{i}\end{array}$ & $\begin{array}{l}110.12189 \\
0.011030379 \\
0.031216\end{array}$ & $\begin{array}{l}1 \\
2 \\
1\end{array}$ & $\begin{array}{r}110.121898 \\
0.005515 \\
0.031216\end{array}$ & $\begin{array}{c}34124 \\
1.71 \\
9.67\end{array}$ & $\begin{array}{l}2.26 \times 10^{-125} \\
0.186 \\
0.00246\end{array}$ \\
\hline
\end{tabular}


and $\sim 0.2 \mathrm{~g}(\sim 6, \sim 10$ and $\sim 25 \mathrm{~mm}$ in standard length; M. Yagi and S. Oikawa, unpublished data) during the transitional phases were accompanied by morphological and behavioural changes. At $\sim 0.002 \mathrm{~g}$ larvae, rapid increment of swimming velocity was observed $^{45}$. At $\sim 0.01 \mathrm{~g}$, the transformation from larval to juvenile stage occurs ${ }^{46}$. Fukuhara ${ }^{46}$ also reported that a relatively sharp increment of maximum swimming speed was observed for $\sim 0.01$ g juveniles. At $\sim 0.2$ g, juveniles are observed to migrate from their nursery grounds to offshore habitats. This migration is also associated with the shift of feeding habits from mysids to fish ${ }^{47}$. Thus, our results suggest that developmental stages of ontogenetic phase shifts in metabolism may be more appropriate to explain behavioural and eco-physiological traits during early life stages of fishes. In fact, there is evidence that, in the tiger puffer, increases in $a_{i}$ (metabolic rate) facilitate anti-predator adaptation, in which the majority of intracohort predation occurs on smaller fish that had a lower metabolic rate $^{22}$. Individuals that enter the next metabolic phase with higher metabolic rate are considered to become stronger, with higher motility accompanying morphological and behavioural changes than extrapolated from the previous metabolic phase with lower metabolic rate ${ }^{22}$. Future studies should investigate the cellular, tissular and physiological mechanisms associated with ontogenetic phase shifts in metabolism, and their possible relevance to prey-predator interactions in nature.

\section{Methods}

Fish used. Fish (P. olivaceus) were hatched from artificially fertilized eggs obtained from wild parents in the northern part of Kyushu, Japan that were captured by fishermen. Experiments were conducted at the Fisheries Research Laboratory, Kyushu University, Fukuoka, Japan in 2005 and 2006. All larvae and juveniles were maintained in aerated $500 \mathrm{l}$ tanks supplied with a constant flow of seawater and fed live rotifers, Brachionus rotundiformis twice daily between 2 and $22 \mathrm{DAH}$ $\left(\sim 5000 \mathrm{l}^{-1}\right)$, live brine shrimp, Artemia sp. larvae twice daily two times between 20 and $32 \mathrm{DAH}\left(\sim 2000 \mathrm{l}^{-1}\right)$, and artificial diets three times daily thereafter. Live diets were fortified with essential fatty acids, EPA and DHA using Super Capsule Powder (Chlorella Industry, Tokyo, Japan), before feeding. The water temperature in the rearing tanks was held at $18^{\circ} \mathrm{C}$ (this temperature was chosen to approximate conditions experienced by the early life stages of the flounder in the wild and was also used when measuring the oxygen consumption). Fish used in the respirometry study were not fed for 3 to $24 \mathrm{~h}$ before experiments, depending on the fish body size, and so the individuals used for respirometry did not have food in their guts. All experimental procedures were approved by a KU committee and conducted in accordance with the Guideline for the Care and Use of Laboratory Animals of Japan, with registrations of M.Y. and S.O. for Animal Experiments in the Faculty of Agriculture and in the Graduate Course of KU.

Respirometry. Oxygen consumption $\left(\dot{V}_{\mathrm{O}_{2}}\right)$ was measured in larval and juvenile fish ranging in size between $0.00026 \mathrm{~g}$ (wet body mass, $0 \mathrm{DAH})$ and $0.90 \mathrm{~g}(80 \mathrm{DAH})$. Resting routine rates of oxygen consumption, i.e. intermediate between the resting and routine activity states ${ }^{48}$, were determined in fasted larvae and juveniles at $18^{\circ} \mathrm{C}$ using one of two methods depending on the developmental stage of the fish, a closed method and a semi-closed method, based on previous studies ${ }^{22,32}$. The larvae and juveniles were placed in the respiration chamber and allowed to settle for an appropriate acclimatisation period before measurement to remove possible stress caused by handling ( $1 \mathrm{~h}$ for the closed method and 1 to $4 \mathrm{~h}$ for the semi-closed method). The closed method was only used for larvae just after hatching to $8 \mathrm{DAH}$, because of their poor swimming ability. The closed method was based on depletion of oxygen in water in a sealed glass oxygen bottle $(20 \mathrm{ml})$. A blank chamber without fish was used to eliminate background respiration. The semi-closed method was essentially a closed method in which the glass chamber was slowly flushed with airsaturated water before determination and closed during determination. Several respiration chambers (50 to $650 \mathrm{ml}$ ) were used depending on the fish body size (50 ml for 8-25 DAH, $100 \mathrm{ml}$ for 18-44 DAH, $250 \mathrm{ml}$ for 46-63 DAH, $350 \mathrm{ml}$ for 46-80 DAH, $650 \mathrm{ml}$ for 63-80 DAH). In the semi-closed method, the bottle which received water flowing out of the respiration chamber was used as the blank chamber. This bottle was sealed at the beginning of determination of oxygen consumption by fish, placed in the water bath for the respiration chamber during determination, and the oxygen concentration in the bottle was determined at the end of the measurement. By using this value as the initial oxygen concentration in the respiration chamber, background respiration was cancelled.

Wet body mass of experimental fish was directly determined immediately after respirometry, except for specimens used in the closed method. Wet body mass during the larval stage was determined as detailed by Yagi et al. ${ }^{22}$. In the closed method, body mass was indirectly estimated from other co-cultured individuals of similar body size, because they were fixed when the dissolved oxygen concentration of water in the respiration chamber was determined by the Winkler's titration method.
Data analysis. Rates of oxygen consumption $\left(\dot{V}_{\mathrm{O}_{2}}\right)$ for the Japanese flounder were plotted on $\log _{10}$ plots against wet body mass $(M)$, and four negative allometric relationships were fitted between $\dot{V}_{O 2}$ and $M$, based on the developmental stages, which is similar to the tiger puffer Takifugu rubripes ${ }^{22}$, interposing three transitional phases of $\dot{V}_{O 2}$ at approximately $0.002,0.01$ and $0.2 \mathrm{~g}$ of wet body mass. For the tiger puffer, at approximately $\sim 0.002 \mathrm{~g}$, the primordia of the fin rays, at $\sim 0.01$ g postflexion larvae metamorphosed into juveniles, and at $\sim 0.1 \mathrm{~g}$ squamation of the body proceeded $^{22}$. For the Japanese flounder, at approximately $\sim 0.002 \mathrm{~g}$ larvae, the ventral fin buds are present and the base of the dorsal and anal fins (primordia) appear, at $\sim 0.01 \mathrm{~g}$, development of fin rays is completed, and at $\sim 0.2 \mathrm{~g}$, squamation on the caudal peduncle is completed, consisting of eight scale rows ${ }^{46}$. Thus, in this study, three transitional phases of $\dot{V}_{O 2}$ at approximately $0.002(0.0015-0.0020 \mathrm{~g}), 0.01$ $(0.010-0.015 \mathrm{~g})$ and $0.2(0.15-0.22 \mathrm{~g}) \mathrm{g}$ of wet body mass were interposed. Sizescaling analyses were performed by applying the statistical model described in Yagi et al. ${ }^{22}$.

1. Kleiber, M. Body size and metabolism. Hilgardia 6, 316-353; DOI:10.3733/ hilg.v06n11p315 (1932).

2. Hemmingsen, A. M. Energy metabolism as related to body size and respiratory surfaces and its evolution. Rep. Steno Mem. Hosp. Nord. Insulin Lab. 9, 1-110 (1960).

3. Peters, R. H. The Ecological Implications of Body Size (Cambridge University Press, Cambridge 1983).

4. Lovegrove, B. G. The zoogeography of mammalian basal metabolic rate. Am. Nat 156, 201-219; DOI:10.1086/303383 (2000).

5. Czarnołęski, M., Kozłowski, J., Stańczykowska, A. \& Lewandowski, K. Optimal resource allocation explains growth curve diversity in zebra mussels. Evol. Ecol. Res. 5, 571-587 (2003).

6. Kozłowski, J., Konarzewski, M. \& Gawelczyk, A. Cell size as a link between noncoding DNA and metabolic rate scaling. Proc. Natl. Acad. Sci. USA 100, 14080-14085; DOI:10.1073/pnas.2334605100 (2003).

7. Capellini, I., Venditti, C. \& Barton, R. A. Phylogeny and metabolic scaling in mammals. Ecology 91, 2783-2793; DOI:10.1890/09-0817.1 (2010).

8. Brody, S. Bioenergetics and Growth (Reinhold Publishing Corporation, New York 1945).

9. Zeuthen, E. Oxygen uptake as related to body size in organisms. Quart. Rev. Biol. 28, 1-12; DOI:10.1086/399308 (1953).

10. Heusner, A. A. Energy metabolism and body size. I. Is the 0.75 mass exponent of Kleiber's equation a statistical artifact? Respir. Physiol. 48, 1-12; DOI:10.1016/ 0034-5687(82)90046-9 (1982).

11. Schmidt-Nielsen, K. Scaling: Why is Animal Size so Important? (Cambridge University Press, Cambridge 1984).

12. West, G. B., Brown, J. H. \& Enquist, B. J. A general model for the origin of allometric scaling laws in biology. Science 276, 122-126; DOI:10.1126/ science.276.5309.122 (1997)

13. White, C. R., Phillips, N. F. \& Seymour, R. S. The scaling and temperature dependence of vertebrate metabolism. Biol. Lett. 2, 125-127; DOI:10.1098/ rsbl.2005.0378 (2006)

14. Moses, M. E. et al. Revisiting a model of ontogenetic growth: estimating model parameters from theory and data. Am. Nat. 171, 632-645; DOI:10.1086/587073 (2008).

15. Kozłowski, J. \& Weiner, J. Interspecific allometries are by-products of body size optimization. Am. Nat. 149, 352-380; DOI:10.1086/285994 (1997).

16. Glazier, D. S. Beyond the '3/4-power law': variation in the intra- and interspecific scaling of metabolic rate in animals. Biol. Rev. 80, 611-662; DOI:10.1017/ S1464793105006834 (2005)

17. Packard, G. C. \& Birchard, G. F. Traditional Allometric analysis fails to provide a valid predictive model for mammalian metabolic rates. J. Exp. Biol. 211, 3581-3587; DOI:10.1242/jeb.023317 (2008).

18. Kolokotrones, T., Savage, V., Deeds, E. J. \& Fontana, W. Curvature in metabolic scaling. Nature 464, 753-756; DOI:10.1038/nature08920 (2010).

19. Mori, S. et al. Mixed-power scaling of whole-plant respiration from seedlings to giant trees. Proc. Natl. Acad. Sci. USA 107, 1447-1451; DOI:10.1073/ pnas.0902554107 (2010).

20. Wieser, W. A distinction must be made between the ontogeny and the phylogeny of metabolism in order to understand the mass exponent of energy metabolism. Respir. Physiol. 55, 1-9; DOI:10.1016/0034-5687(84)90112-9 (1984).

21. Czarnołęski, M. et al. Scaling of metabolism in Helix aspersa snails: changes through ontogeny and response to selection for increased size. J. Exp. Biol. 211, 391-400; DOI:10.1242/jeb.013169 (2008).

22. Yagi, M., Kanda, T., Takeda, T., Ishimatsu, A. \& Oikawa, S. Ontogenetic phase shifts in metabolism: links to development and anti-predator adaptation. Proc. $R$ Soc. Lond. B Biol. Sci. 277, 2793-2801; DOI:10.1098/rspb.2010.0583 (2010).

23. Hunt von Herbing, I. in Comparative Developmental Physiology: Contributions, Tools, and Trends. 83-98 (Oxford University Press, New York 2005).

24. Killen, S. S., Costa, I., Brown, J. A. \& Gamperl, A. K. Little left in the tank: metabolic scaling in marine teleosts and its implications for aerobic scope. Proc. $R$. Soc. Lond. B Biol. Sci. 274, 431-438; DOI:10.1098/rspb.2006.3741 (2007).

25. Moran, D. \& Wells, R. M. G. Ontogenetic scaling of fish metabolism in the mouseto-elephant mass magnitude range. Comp. Biochem. Physiol. A. Mol. Integr. Physiol. 148, 611-620; DOI:10.1016/j.cbpa.2007.08.006 (2007). 
26. Bokma, F. Evidence against universal metabolic allometry. Funct. Ecol. 18, 184-187; DOI:10.1111/j.0269-8463.2004.00817.x (2004)

27. Glazier, D. S. The 3/4-power law is not universal: evolution of isometric, ontogenetic metabolic scaling in pelagic animals. BioScience 56, 325-332; DOI:10.1641/0006-3568(2006)56\%5B325:TPLINU\%5D2.0.CO;2 (2006).

28. Glazier, D. S. et al. Ecological effects on metabolic scaling: amphipod responses to fish predators in freshwater springs. Ecol. Monogr. 81, 599-618; DOI:10.1890/110264.1 (2011).

29. Clarke, A. \& Johnston, N. M. Scaling of metabolic rate with body mass and temperature in fish. J. Anim. Ecol. 68, 893-905; DOI:10.1046/j.13652656.1999.00337.x (1999).

30. Wieser, W. Energetics of fish larvae, the smallest vertebrates. Acta Physiol. Scand. 154, 279-290; DOI:10.1111/j.1748-1716.1995.tb09912.x (1995).

31. Giguère, L. A., Côté, B. \& St-Pierre, J.-F. Metabolic rates scale isometrically in larval fishes. Mar. Ecol. Prog. Ser. 50, 13-19; DOI:10.3354/meps050013 (1988).

32. Oikawa, S., Itazawa, Y. \& Gotoh, M. Ontogenetic change in the relationship between metabolic rate and body mass in a sea bream Pagrus major (Temminck \& Schlegel). J. Fish Biol. 38, 483-496; DOI:10.1111/j.1095-8649.1991.tb03136.x (1991).

33. Post, J. R. \& Lee, J. A. Metabolic ontogeny of teleost fishes. Can. J. Fish. Aquat. Sci. 53, 910-923; DOI:10.1139/cjfas-53-4-910 (1996).

34. Finn, R. N., Ronnestad, I., van der Meeren, T. \& Fyhn, H. J. Fuel and metabolic scaling during the early life stages of Atlantic cod Gadus morhua. Mar. Ecol. Prog. Ser. 243, 217-234; DOI:10.3354/meps243217 (2002).

35. Brownlee, K. A. Statistical Theory and Methodology in Science and Engineering (Wiley, New York 1965).

36. Feldman, H. A. \& McMahon, T. A. The $3 / 4$ mass exponent for energy metabolism is not a statistical artifact. Respir. Physiol. 52, 149-163; DOI:10.1016/00345687(83)90002-6 (1983).

37. Rombough, R. J. in Fish Physiology, Volume VI. 59-161 (Academic Press, San Diego 1988).

38. Kaufmann, R. Respiratory cost of swimming in larval and juvenile cyprinids. J. Exp. Biol. 150, 343-366 (1990).

39. Bochdansky, A. B. \& Leggett, W. C. Winberg revisited: convergence of routine metabolism in larval and juvenile fish. Can. J. Fish. Aquat. Sci. 58, 220-230; DOI:10.1139/cjfas-58-1-220 (2001)

40. Wuenschel, M. J., Werner, R. G. \& Hoss, D. E. Effect of body size, temperature, and salinity on the routine metabolism of larval and juvenile spotted seatrout. J. Fish Biol. 64, 1088-1102; DOI:10.1111/j.1095-8649.2004.00374.x (2004).

41. Sears, K. E., Kerkhoff, A. J., Messerman, A. \& Itagaki, H. Ontogenetic scaling of metabolism, growth, and assimilation: testing metabolic scaling theory with Manduca sexta larvae. Physiol. Biochem. Zool. 85, 159-173; DOI:10.1086/664619 (2012).

42. Blossman-Myer, B. \& Burggren, W. W. Metabolic allometry during development and metamorphosis of the silkworm, Bombyx mori: analyses, patterns and mechanisms. Physiol. Biochem. Zool. 83, 215-231; DOI:10.1086/648393 (2010).
43. Blaxter, J. H. S. in Fish Physiology, Volume III. 177-252 (Academic Press, New York 1969).

44. Kendall, A. W. Jr., Ahlstrom, E. H. \& Moser, H. G. in Ontogeny and Systematics of Fishes. 11-22 (Allen Press, Kansas 1984).

45. Yasunaga, Y. Measurement of swimming speed of flounder larvae Paralichthys olivaceus with a small straight channel. Nippon Suisan Gakkaishi 51, 227-231; DOI:10.2331/suisan.51.227 (1985).

46. Fukuhara, O. Morphological and functional development of Japanese flounder in early life stage. Nippon Suisan Gakkaishi 52, 81-91; DOI:10.2331/suisan.52.81 (1986).

47. Kato, K. Study on resources management of flounder (Paralichthys olivaceus) in the northern coast of Niigata. I. Distribution and food habit of juvenile flounders. Bull. Niigata. Pre. Fish. Exp. Sta. 12, 27-41 (1987). (in Japanese with English abstract).

48. Cech Jr, J. J. in Methods for Fish Biology. 335-362 (American Fisheries Society, Bethesda 1990).

\section{Acknowledgments}

This work was partly supported by grants from the Sasakawa Science Research Foundation from The Japan Science Society to M.Y. [grant \#23-749], and the Ministry of Education, Culture, Sports, Science and Technology of Japan to S.O. [grant \#16580152]. We thank $\mathrm{K}$. Taniguchi for assistance in rearing the fish.

\section{Author contributions}

M.Y. and S.O. conceived of and designed the research. M.Y. cared for research animals. M.Y. and S.O. collected, processed and interpreted data. M.Y. drafted the manuscript. All authors read and commented on the manuscript.

\section{Additional information}

Competing financial interests: The authors declare no competing financial interests.

How to cite this article: Yagi, M. \& Oikawa, S. Ontogenetic phase shifts in metabolism in a flounder Paralichthys olivaceus. Sci. Rep. 4, 7135; DOI:10.1038/srep07135 (2014).

This work is licensed under a Creative Commons Attribution-NonCommercialShareAlike 4.0 International License. The images or other third party material in this article are included in the article's Creative Commons license, unless indicated otherwise in the credit line; if the material is not included under the Creative Commons license, users will need to obtain permission from the license holder in order to reproduce the material. To view a copy of this license, visit http:// creativecommons.org/licenses/by-nc-sa/4.0/ 